\title{
Fluid responsiveness prediction using Vigileo FloTrac measured cardiac output changes during passive leg raise test
}

\author{
Anton Krige ${ }^{1^{*}}$ (D) Martin Bland ${ }^{1}$ and Thomas Fanshawe ${ }^{2}$
}

\begin{abstract}
Background: Passive leg raising (PLR) is a so called self-volume challenge used to test for fluid responsiveness. Changes in cardiac output (CO) or stroke volume (SV) measured during PLR are used to predict the need for subsequent fluid loading. This requires a device that can measure CO changes rapidly. The Vigileo ${ }^{\mathrm{TM}}$ monitor, using third-generation software, allows continuous CO monitoring. The aim of this study was to compare changes in CO (measured with the Vigileo device) during a PLR manoeuvre to calculate the accuracy for predicting fluid responsiveness.
\end{abstract}

Methods: This is a prospective study in a 20-bedded mixed general critical care unit in a large non-university regional referral hospital. Fluid responders were defined as having an increase in CO of greater than $15 \%$ following a fluid challenge. Patients meeting the criteria for circulatory shock with a Vigileo ${ }^{\mathrm{TM}}$ monitor (Vigileo ${ }^{\mathrm{TM}}$; FloTrac; Edwards ${ }^{\mathrm{TM}}$; Lifesciences, Irvine, CA, USA) already in situ, and assessed as requiring volume expansion by the clinical team based on clinical criteria, were included. All patients underwent a PLR manoeuvre followed by a fluid challenge.

Results: Data was collected and analysed on stroke volume variation (SW) at baseline and CO and SW changes during the PLR manoeuvre and following a subsequent fluid challenge in 33 patients. The majority had septic shock. Patient characteristics, baseline haemodynamic variables and baseline vasoactive infusion requirements were similar between fluid responders (10 patients) and non-responders (23 patients). Peak increase in CO occurred within $120 \mathrm{~s}$ during the PLR in all cases. Using an optimal cut point of $9 \%$ increase in CO during the PLR produced an area under the receiver operating characteristic curve of 0.85 ( $95 \% \mathrm{Cl} 0.63$ to 1.00) with a sensitivity of $80 \%$ (95\% Cl 44 to $96 \%$ ) and a specificity of $91 \%$ (95\% Cl 70 to $98 \%$ ).

Conclusions: $\mathrm{CO}$ changes measured by the Vigileo ${ }^{\mathrm{TM}}$ monitor using third-generation software during a PLR test predict fluid responsiveness in mixed medical and surgical patients with vasopressor-dependent circulatory shock.

Keywords: Passive leg raising, Edwards Vigileo FloTrac monitoring, Fluid responsiveness, Cardiac output monitoring, Vasoplegic shock, Septic shock,

\section{Background}

Circulatory insufficiency is common in critically ill patients and may lead to organ dysfunction. Increasing cardiac preload may increase stroke volume (SV) and consequently cardiac output $(\mathrm{CO})$ and thus tissue perfusion [1]. However, it has been shown that only half of critically ill patients thought to be preload responsive,

\footnotetext{
* Correspondence: anton.krige@elht.nhs.uk

'Department of Anaesthesia and Critical Care, Royal Blackburn Hospital,

Haslingden Road, Blackburn, UK

Full list of author information is available at the end of the article
}

based on static predictors of preload, actually show an increase in $\mathrm{SV}$, and therefore $\mathrm{CO}$, following volume expansion (VE) $[2,3]$. The administration of fluid in the group that is not preload responsive not only delays the appropriate management of their circulatory insufficiency but is also an independent predictor of delayed respiratory weaning and survival [4-11].

Functional haemodynamic monitoring has been shown to accurately predict fluid responsiveness but unfortunately several caveats, which include constant tidal volumes of adequate size and sinus rhythm, must be 
present [12-17]. Unfortunately, this precludes a large proportion of critically ill patients.

Passive leg raising (PLR), whereby the patients legs are transiently raised by $45^{\circ}$, and the torso flattened, results in a reversible flow of $150-300 \mathrm{ml}$ of blood from the venous capacitance vessels of the lower body, to the thoracic compartment, a so called self-volume challenge [18-20]. Boulain et al. [21] first demonstrated the potential of this phenomenon to predict fluid responsiveness by measuring blood pressure changes during a PLR.

Subsequent studies have shown even greater accuracy, without the limitations of functional haemodynamic monitoring, using a variety of minimally invasive devices capable of rapid measurement of changes in flow or stroke volume during PLR. Examples include esophageal Doppler [22, 23], transthoracic Doppler ultrasound [24], transthoracic echocardiography (TTE) [25-29], pulse contour techniques [28, 30-33], bioreactance [34-36], end tidal carbon dioxide change [37] and bio-impedance cardiography [38]. These studies have been summarised in three recent systematic reviews [39-41], and all reported a high sensitivity regarding prediction of fluid responsiveness (all three reported the same pooled area under the receiver operating characteristic curve (AUC) of 0.95 , with similar confidence intervals).

Only one of these [28] studies used the Vigileo ${ }^{\mathrm{Tw}}$ monitor but with second-generation software.

The aim of this study was to assess the accuracy of the Vigileo $^{\mathrm{mm}}$ monitor (Vigileo ${ }^{\mathrm{mm}}$; FloTrac; Edwards ${ }^{\mathrm{m}}$; Lifesciences, Irvine, CA, USA) using third-generation software (version 3.02), in predicting preload responsiveness by measuring changes in CO during a PLR manoeuvre, in a mixture of medical and surgical critically ill patients with circulatory shock, with or without spontaneous breathing efforts or arrhythmias. In addition, we included an assessment of the accuracy of stroke volume variation (SVV) measured by the same device to predict responsiveness. We evaluated a cut point of $9.6 \%$ at baseline (derived by Li et al. [42]), and the change in SVV during PLR were both evaluated as predictors of fluid responsiveness.

\section{Methods}

\section{Patients}

This prospective study was conducted on a mixed medical and surgical general critical care unit in a large nonuniversity regional referral hospital. The study received research ethics committee approval and patients were enrolled following written informed consent.

\section{Inclusion criteria}

Critical care patients, over 18 years of age, requiring a fluid challenge as decided by the attending critical care physician, were included. The research team had no influence over this decision, and patients were only approached for enrolment following the decision to administer a fluid challenge.

This decision was based on the presence of at least one clinical sign of inadequate tissue perfusion, i.e. (a) systolic blood pressure $<90 \mathrm{mmHg}$ (or a decrease of $>50 \mathrm{mmHg}$ in previously hypertensive patients) or the need for vasoconstrictor drugs (vasopressin or norepinephrine); (b) urine output $<0.5 \mathrm{ml} / \mathrm{kg} / \mathrm{h}$ for $\geq 2 \mathrm{~h}$; (c) tachycardia (heart rate $>100 / \mathrm{min}$ ); or (d) presence of skin mottling.

The Vigileo system (Edwards Lifescience, Irvine, CA) with arterial pressure waveform analysis device via special blood flow sensor (FloTrac Sensor, Edwards Lifesciences, Irvine, CA) using third-generation software must already be in situ.

\section{Exclusion criteria}

Any patients that were unable to perform PLR and who had any contraindications to fluid challenge, defined as life-threatening hypoxaemia, and evidence of blood volume overload and/or hydrostatic pulmonary oedema, were excluded.

\section{Measurements}

All haemodynamic data was continuously recorded on a Draeger monitoring system and a Vigileo system (Edwards Lifesciences, Irvine, CA) using third-generation software (version 3.02).

\section{VigileoTM monitor measurements}

The FloTrac transducer (FloTracTM, Edwards Lifesciences, Irvine, CA, USA) connected the indwelling arterial line to the VigileoTM System (Edwards Lifesciences, Irvine, CA, USA). This non-calibrated continuous CO monitor software analyses the arterial waveform with a frequency of a $100 \mathrm{~Hz}$ over $20 \mathrm{~s}$. SV is calculated as $k \times$ pulsatility, where pulsatility is the standard deviation of arterial pressure over the preceding $20 \mathrm{~s}$, and $k$ is a factor which describes vascular compliance and resistance over the preceding 1 to $5 \mathrm{~min}$, depending on the setting. This factor (so called proprietary Dynamic Tone Technology) is derived from a multivariate regression model taking into account Langewouter's aortic compliance [43], mean arterial pressure (MAP), along with variance, skewness, and kurtosis of the arterial pressure wave [43, 44]. A greater number of hyperdynamic and vasodilated patients were incorporated into the algorithm database, and additional physiologically based variables were added to the algorithm's vascular tone $k$ factor in order to adjust automatically for hyperdynamic and vasodilated patients in the third-generation software update. This has increased the accuracy of SV measurement in vasodilated patients [45-47]. 


\section{Other measurements}

The presence of any arrhythmias was recorded. Respiratory data was collated regarding the mode of ventilation, presence of spontaneous respiratory efforts, peak inspiratory pressures, plateau pressures, PEEP value and tidal volume. Dosages of any vasoactive drugs were recorded.

\section{Study design}

The study design is illustrated in Fig. 1. The following peak haemodynamic parameters were all recorded at each of the four stages in the protocol: heart rate (HR), mean arterial pressure (MAP), central venous pressure (CVP), cardiac index (CI), CO, SV, stroke volume index (SVI) and stroke volume variation (SVV). At the first baseline stage, measurements were taken while the patient was $45^{\circ}$ semi-recumbent. During the next stage (PLR), the remote control of the bed was used to tilt the trunk to a horizontal position, and the legs were tilted $45^{\circ}$ upwards. The patient was then returned to the $45^{\circ}$ semirecumbent position until the haemodynamic parameters stabilised to similar values as the original baseline. These values were recorded as representing the second baseline stage. Following this, a VE of $250 \mathrm{ml}$ of Gelofusine ${ }^{\mathrm{R}}$ was administered at the maximum rate allowed by the volumetric pump (within $15 \mathrm{~min}$ ). The final stage, denoted as post volume expansion (PVE), occurred immediately following the fluid challenge, when all haemodynamic parameters were recorded once again.

\section{Statistical analysis}

Continuous data are reported as mean and standard deviation or median and inter-quartile range. A change in $\mathrm{CO}$ from baseline of $>15$ and $<15 \%$ following the volume challenge was used to classify the patients as 'responders' and 'non-responders', respectively [3]. Measured variables were then compared between responders and nonresponders using $t$ tests, chi-squared tests or Fisher's exact test for low counts, as appropriate for the data type, and reported as $p$ values. The positively skewed variables of time to admission, tidal volume and norepinephrine dose were analysed after log-transforming the original data values. A receiver operating characteristic (ROC) curve was used to measure the sensitivity and specificity of the PLR test to predict responders to the fluid challenge.

$p$ values of less than 0.05 were considered to be statistically significant. Statistical analysis was performed using $\mathrm{R}$ version 2.15.2 [48].

\section{Results}

\section{Patient characteristics}

Thirty-seven patients with $\mathrm{CO}$ monitoring in situ and meeting clinical criteria for a fluid challenge were initially included and four were subsequently excluded. Three had different diagnoses (cardiogenic shock with blood volume overload which was an exclusion criteria), and one had missing baseline and PLR CO data. The data from the remaining 33 patients who received a fluid challenge were analysed. Patient characteristics are summarised in Table 1 and were similar between groups. The majority ( $80 \%)$, overall and in each group, were on a controlled mode of ventilation, with similar tidal volumes between groups. Cardiac arrhythmias were present in $9 \%$ of all patients and balanced between the groups. The aetiology of circulatory insufficiency was septic shock in the majority ( $82 \%)$ and severe systemic inflammatory response syndrome (SIRS) in the remainder.

\section{Baseline haemodynamic variables and vasoactive infusions}

There were no statistically significant differences in baseline haemodynamic variables (Table 2). Vasoactive drug infusions (Table 3) were similar between groups, and only two patients did not receive any vasoactive infusions at the time of the PLR test. Thirty (91\%) patients received a norepinephrine infusion with a mean dose of $0.30(0.17) \mathrm{mcg} / \mathrm{kg} / \mathrm{min}$. Seven patients received Dobutamine, and this was split between responders and non-responders. Vasopressin infusions were used in two patients. It was combined with norepinephrine in one patient and used as sole vasopressor in the other.

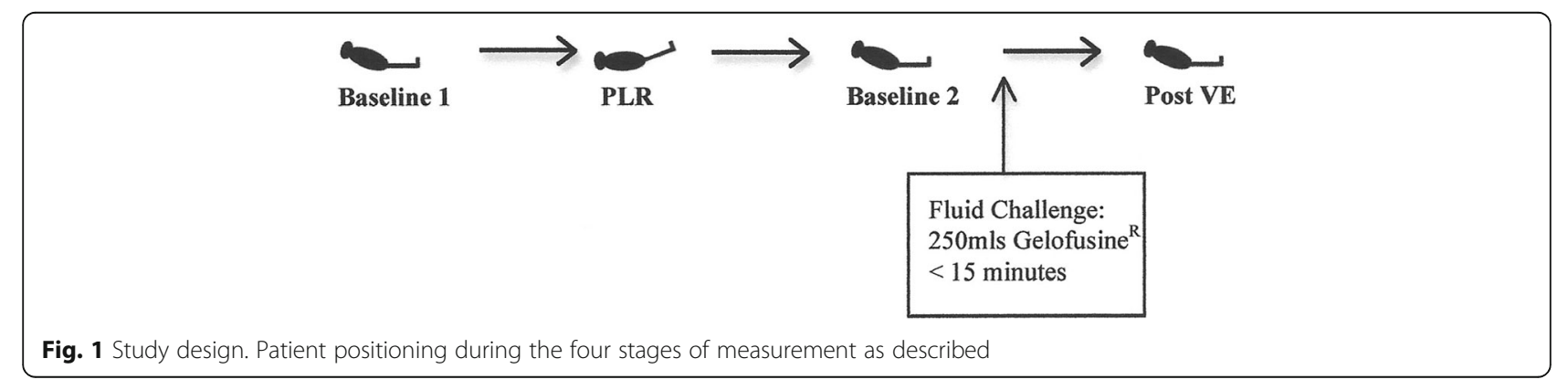


Table 1 Patient characteristics

\begin{tabular}{|c|c|c|c|c|}
\hline & All & Responders & Non-responders & \\
\hline & $n=33$ & $n=10$ & $n=23$ & $p$ \\
\hline Age & $60.0(13.6)$ & $58.4(16.2)$ & $60.7(12.7)$ & 0.70 \\
\hline \multicolumn{5}{|l|}{ Sex } \\
\hline Male & $15(45 \%)$ & $4(40 \%)$ & $11(48 \%)$ & \multirow[t]{2}{*}{0.97} \\
\hline Female & $18(55 \%)$ & $6(60 \%)$ & $12(52 \%)$ & \\
\hline Weight (kg) & $72.1(12.9)$ & $75.0(14.1)$ & $70.9(12.4)$ & 0.44 \\
\hline APACHE I| score & $19.9(6.9)$ & $19.0(5.8)$ & $20.4(7.5)$ & 0.58 \\
\hline \multicolumn{5}{|l|}{ Died in hospital } \\
\hline Yes & $16(48 \%)$ & 7 (70 \%) & $9(39 \%)$ & \multirow[t]{2}{*}{0.21} \\
\hline No & $17(52 \%)$ & $3(30 \%)$ & $14(61 \%)$ & \\
\hline Admission to PLR (h) & $26[18,52]$ & $38[21,102]$ & $26[16,42]$ & 0.25 \\
\hline \multicolumn{5}{|l|}{ Arrhythmia } \\
\hline Present & $3 / 32(9 \%)$ & 1/9 (11\%) & 2/23 (9\%) & \multirow[t]{2}{*}{1.00} \\
\hline Absent & 29/32 (91 \%) & 8/9 (89 \%) & 21/23 (91 \%) & \\
\hline Tidal volume (ml) & $510[463,563]$ & $540[473,660]$ & $491[460,549]$ & 0.39 \\
\hline Plateau pressure $\left(\mathrm{cmH}_{2} \mathrm{O}\right)$ & $26.6(7.1)$ & $26.4(5.5)$ & $26.7(7.7)$ & 0.90 \\
\hline PEEP $\left(\mathrm{cmH}_{2} \mathrm{O}\right)$ & $8.5(2.5)$ & $8.9(2.8)$ & $8.4(2.4)$ & 0.60 \\
\hline Respiratory rate (/min) & $16.8(4.2)$ & $15.5(2.4)$ & $17.3(4.7)$ & 0.15 \\
\hline \multicolumn{5}{|l|}{ Spontaneous breathing } \\
\hline Yes & $6 / 30(20 \%)$ & 2/9 (22\%) & $4 / 21(19 \%)$ & \multirow[t]{2}{*}{1.00} \\
\hline No & 24/30 (80 \%) & $7 / 9(78 \%)$ & 17/21 (81\%) & \\
\hline \multicolumn{5}{|l|}{ Arterial line site: } \\
\hline Femoral & $4(12 \%)$ & $1(10 \%)$ & $3(13 \%)$ & \multirow[t]{2}{*}{1.00} \\
\hline Other (radial and brachial) & $29(88 \%)$ & 9 (90\%) & $20(87 \%)$ & \\
\hline \multicolumn{5}{|l|}{ Diagnostic groups: } \\
\hline Septic shock & $27(82 \%)$ & 7 (70 \%) & $20(87 \%)$ & 0.34 \\
\hline - Endocarditis & $1(3 \%)$ & $0(0 \%)$ & $1(4 \%)$ & - \\
\hline - Occult & $7(21 \%)$ & $2(20 \%)$ & $5(22 \%)$ & - \\
\hline - Peritonitis & $8(24 \%)$ & $2(20 \%)$ & $6(26 \%)$ & - \\
\hline - Pneumonia & $11(33 \%)$ & $3(30 \%)$ & $8(35 \%)$ & - \\
\hline SIRS & $6(18 \%)$ & $3(30 \%)$ & $3(13 \%)$ & - \\
\hline - Ischaemic bowel & $2(6 \%)$ & $1(10 \%)$ & $1(4 \%)$ & - \\
\hline - Occult & $1(3 \%)$ & 0 & $1(4 \%)$ & - \\
\hline - Pancreatico-duodenectomy & $1(3 \%)$ & 0 & $1(4 \%)$ & - \\
\hline - Pancreatitis & $2(6 \%)$ & $2(20 \%)$ & 0 & - \\
\hline
\end{tabular}

Data are shown as mean (standard deviation), median (inter-quartile range), or number (percentage) with $p$ value comparing responders to non-responders for certain characteristics. Sample sizes are as in column headings unless stated (some variables had small numbers of missing values)

\section{Effects of PLR and VE on CO and other haemodynamic variables}

The peak increase in CO occurred within $120 \mathrm{~s}$ in all cases. $\mathrm{CO}$ change during PLR was positively related to subsequent VE (correlation = 0.65) (Fig. 2). Spontaneous breathing and/ or arrhythmia was only present in a few patients in each group thus not allowing any meaningful analysis of the influence of these two factors on the association (Table 1).

\section{Effects of PLR and VE on changes in CO}

The changes in CO induced by PLR were significantly greater in responders than in non-responders $(p=0.02)$. In fluid responders, $\mathrm{CO}$ increased by an average of $1.43 \mathrm{l} / \mathrm{min}$ (95 \% CI 0.53 to 2.33 ) from baseline (average 5.98) to during PLR (average 7.41), corresponding to a $24 \%$ increase from baseline (95\% CI 8 to $39 \%$ ), and by an average of $1.94 \mathrm{l} / \mathrm{min}$ (95 \% CI 0.99 to 2.89 ) from 
Table 2 Haemodynamic variables at baseline

\begin{tabular}{|c|c|c|c|c|}
\hline & $\begin{array}{l}\text { All } \\
n=33\end{array}$ & $\begin{array}{l}\text { Responders } \\
n=10\end{array}$ & $\begin{array}{l}\text { Non-responders } \\
n=23\end{array}$ & $p$ \\
\hline $\mathrm{HR}(/ \mathrm{min})$ & $100(19.5)$ & $106(19.9)$ & $98(19.2)$ & 0.29 \\
\hline CVP (mmHg) & $10.6(5.7)$ & $9.9(6.1)$ & $10.9(5.7)$ & 0.66 \\
\hline MAP $(\mathrm{mmHg})$ & $69.5(10.7)$ & $65.1(8.8)$ & $71.5(11.0)$ & 0.09 \\
\hline $\mathrm{PP}(\mathrm{mmHg})$ & $52.6(13.1)$ & $51.6(17.8)$ & $52.9(11.2)$ & 0.85 \\
\hline SV (ml/beat) & $60.8(14.5)$ & $56.7(16.3)$ & $62.7(13.7)$ & 0.33 \\
\hline $\mathrm{SVI}\left(\mathrm{ml} / \mathrm{m}^{2} /\right.$ beat $)$ & $33.4(7.8)$ & $30.9(8.8)$ & $34.4(7.4)$ & 0.28 \\
\hline $\mathrm{CO}(\mathrm{L} / \mathrm{min})$ & $6.1(1.5)$ & $6.0(1.6)$ & $6.1(1.5)$ & 0.84 \\
\hline $\mathrm{Cl}\left(\mathrm{L} / \mathrm{min} / \mathrm{m}^{2}\right)$ & $3.3(0.8)$ & $3.3(1.0)$ & $3.4(0.8)$ & 0.81 \\
\hline SW (\%) & $14.2(11.0)$ & $18.4(10.5)$ & $12.3(11.0)$ & 0.15 \\
\hline SVR (dynes s/cm5) & $842(347)$ & $917(504)$ & $810(259)$ & 0.54 \\
\hline
\end{tabular}

before VE (average 5.39) to after VE (average 7.33), corresponding to a $35 \%$ increase from baseline (95\% CI 24 to $47 \%)$.

In fluid non-responders, $\mathrm{CO}$ increased by an average of $0.24 \mathrm{l} / \mathrm{min}$ (95 \% CI 0.09 to 0.39 ) from baseline (average 6.10) to during PLR (average 6.34), corresponding to a $3 \%$ increase from baseline ( $95 \%$ CI 1 to $6 \%$ ), and by an average of $0.45 \mathrm{l} / \mathrm{min}$ (95\% CI 0.31 to 0.59 ) from before VE (average 5.94) to after VE (average 6.39), corresponding to a $7 \%$ increase from baseline (95\% CI 5 to $10 \%)$.

Seven patients had an insignificant reduction in their CO during PLR (Fig. 2).

\section{Prediction of fluid responsiveness}

The ROC curve (Fig. 3) shows the varying predictive performance of the PLR test as the cut point changes. The optimal cut point on the ROC curve for this dataset was approximately $9 \%$, i.e. an increase in $\mathrm{CO}$ of $9 \%$ or greater during PLR predicts fluid responsiveness with the greatest accuracy generating a sensitivity of $80 \%$ (95\% CI 44 to $96 \%$ ) and a specificity of $91 \%$ (95\% CI 70 to $98 \%)$.

Although there was little distinction between a range of 10 to $15 \%$ (for a $15 \%$ cut point the sensitivity and

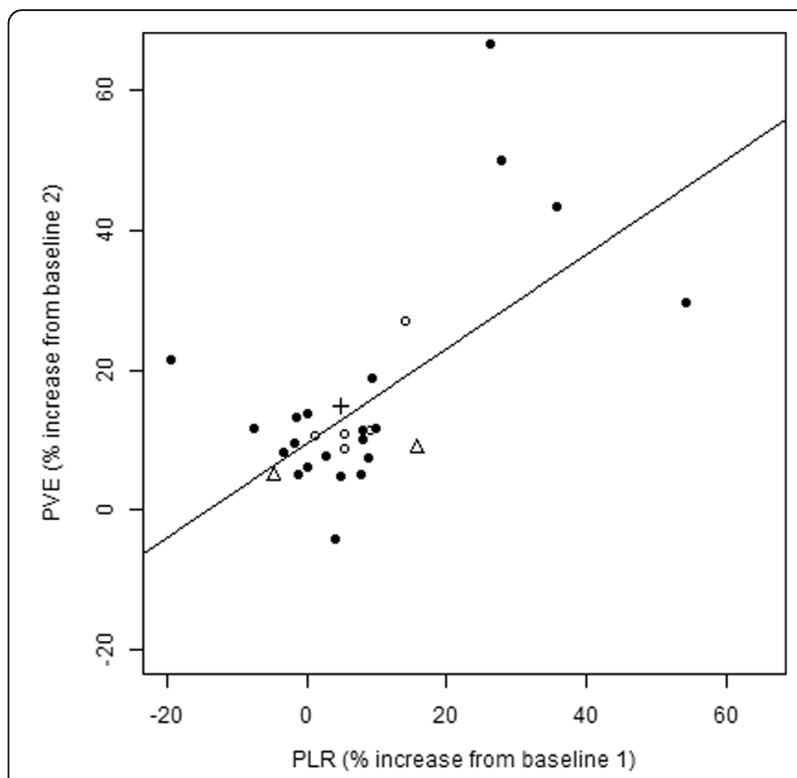

Fig. 2 Relationship between percentage increase in cardiac output from baseline 1 after PLR and PVE after baseline 2 and line of best fit (correlation $=0.65$ ). Open circles are patients with spontaneous breathing efforts; triangles are patients with arrhythmias; crosses are patients with both spontaneous breathing efforts and arrhythmias, and black circles are patients with neither spontaneous breathing efforts nor arrhythmias

specificity was $60 \%$ (95\% CI 27 to $86 \%$ ) and 96 (95\% CI 76 to $99.8 \%$ ), the positive and negative predictive values were $86 \%$ (695\% CI 42 to $99 \%$ ) and $85 \%$ (95\% CI 64 to $95 \%)$, respectively).

The area under the empirical ROC curve was 0.85 (95\% CI 0.63 to 1.00 ).

Using the increase in SVV during the PLR test as the predictor provides no better predictive performance than would be expected by chance with an area under the ROC curve of 0.56 (95\% CI 0.34 to 0.77 ).

An SVV cut point of $9.6 \%$ at baseline, rather than change during PLR, as the predictor of fluid responsiveness, gives an area under the ROC curve of 0.74 (95\% CI 0.53 to 0.91 ), with $70 \%$ sensitivity and $57 \%$ specificity.

\section{Discussion}

Our study shows that changes in $\mathrm{CO}$ measured using the Vigileo ${ }^{\mathrm{TM}}$ monitor during a PLR manoeuvre is a useful

Table 3 Vasoactive drug infusions

\begin{tabular}{|c|c|c|c|c|}
\hline & All & Responders & Non-responders & $p$ \\
\hline Norepinephrine (mcg/kg/min) & $0.28(0.20,0.36)(n=30)$ & $0.31(0.16,0.37)(n=10)$ & $0.28(0.21,0.34)(n=20)$ & 0.92 \\
\hline Vasopressin (mcg/min) & - & $4.5(n=1)$ & $3.0(n=1)^{a}$ & - \\
\hline Dobutamine (mcg/kg/min) & $4.6(1.2)(n=7)$ & $4.4(1.3)(n=4)$ & $4.8(1.2)(n=3)$ & - \\
\hline
\end{tabular}

Data are shown as mean (standard deviation) or median (inter-quartile range), and number of patients ( $n$ ) ( $p$ value compares dose between responders and nonresponders in the case of norepinephrine). In the case of vasopressin, the only dose is given, as there was one patient only in each group

${ }^{a}$ The only patient requiring vasopressor support that did not include norepinephrine 


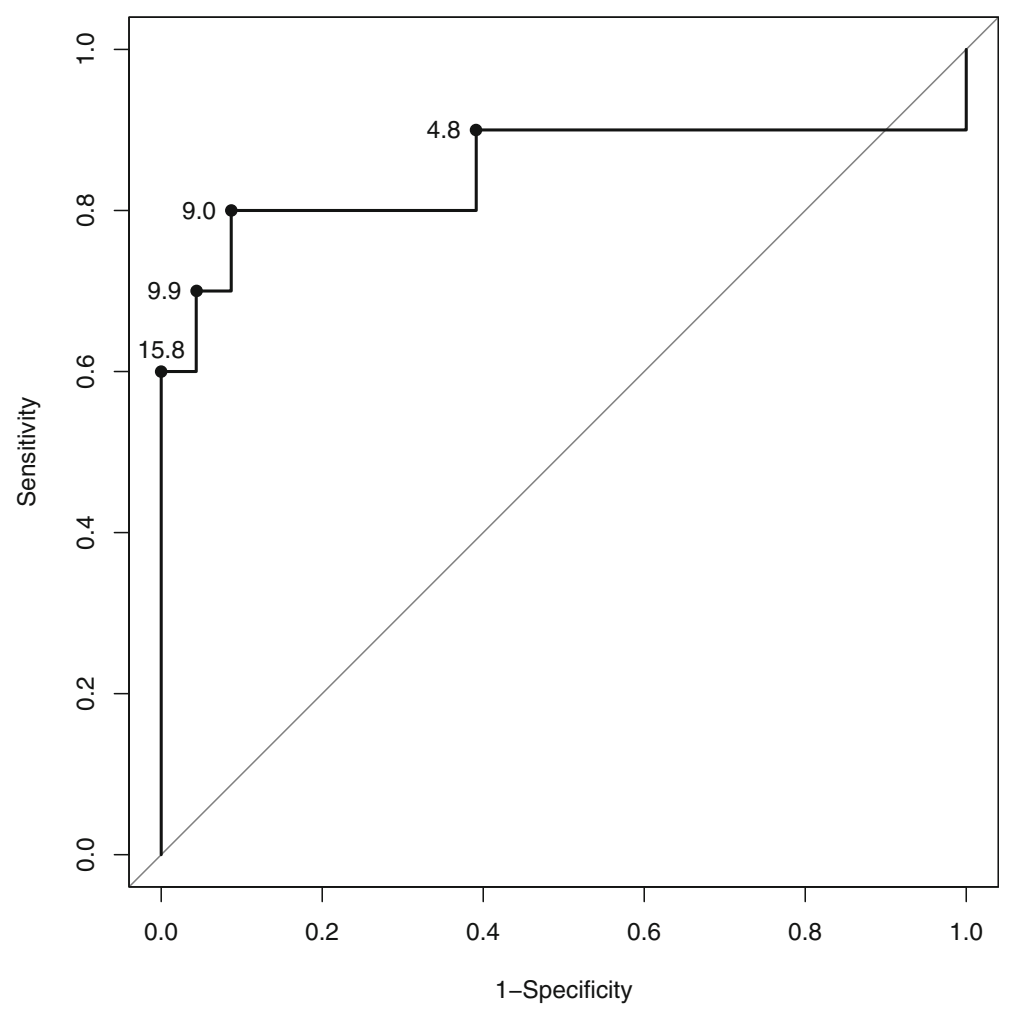

Fig. 3 ROC curve demonstrating predictive performance after PLR on cardiac output response to PVE (AUC 0.85). Figures on the curve indicate the relevant cut point of cardiac output response (\% change from baseline)

predictor of fluid responsiveness in mixed critically ill patients with vasopressor-dependent circulatory shock. An increase in $\mathrm{CO}$ of $\geq 9 \%$ during the PLR predicted an increase in $\mathrm{CO}$ of $\geq 15 \%$ following subsequent volume expansion with good sensitivity $(80 \%)$ and specificity (91\%) resulting in an AUC of 0.85 (95\% CI 0.63 to 1.00). The high specificity has the potential to avoid the deleterious effects of unnecessary volume expansion in this patient group $[4,6,7,11]$.

Our results were consistent with previous validation studies of the PLR manoeuvre [21-38, 49] which are encapsulated in three recent systematic reviews [39-41]. These included nine, 21 and 23 studies assessing a total of 353, 991 and 1013, patients respectively. Our results were similar to the only other study using the Vigileo FloTrac device conducted by Biais et al. [14]. They reported a sensitivity of $85 \%$ and a specificity of $90 \%$ with a sample size of 34 patients and a peak change in flow within $120 \mathrm{~s}$. Their study differed from our study in the following respects. They used second-generation FloTrac software whereas we used third-generation FloTrac software. Almost all the patients in the Biais study were surgical as opposed to an even split between medical and surgical in our study. The patients in our sample were much sicker, i.e. only $65 \%$ were invasively ventilated in their study and all were breathing spontaneously with none receiving vasoactive drugs. That is in contrast with our study where all the patients were invasively ventilated and receiving vasoactive drugs (mean norepinephrine dosage was $0.3 \pm 0.17 \mathrm{mcg} / \mathrm{kg} / \mathrm{min}$ ). We reported a high APACHE2 score and hospital mortality.

Our study had the following limitations. Firstly, we identified less than one third of our sample as fluid responders (ten out of 33 subjects), whereas $50 \%$ of patients were identified as responders in the systematic review by Michard et al. [3] and similarly in the PLR systematic reviews [39-41]. This may have weakened our calculated sensitivity and specificity. Responders were defined using a cut off of $15 \%$, as this definition was used consistently throughout the other published PLR studies [21-41, 49, 50], and we used the recommended PLR manoeuvre, i.e. patients started from a semi-recumbent position. This has been indentified as essential to ensure that splanchnic blood redistribution occurs thereby ensuring an adequate selfvolume challenge [49].The small sample size and the volume chosen for our fluid challenges may have contributed to this lower rate of fluid responders. However, the sample size was still larger than half of all other PLR studies published [21-38, 49]. We chose $250 \mathrm{ml}$ of Gelofusine for our fluid challenges as this was a pragmatic study which followed the local clinical practice at that time. Although most of the studies in the systematic reviews [39-41] used volumes of $500 \mathrm{ml}$, the study by Kang et al. [31] used 
$250 \mathrm{ml}$, and the study by Boulain et al. [21] used $300 \mathrm{ml}$ of Gelatin. Both of these studies reported the usual rate of fluid responders and the Kang et al. study reported very high sensitivity and specificity. Boulain et al. discussed the rationale for choosing that volume, i.e. it is roughly equal to the volume of blood redistributed by the PLR manoeuvre. The volume and type of fluid we used were also consistent with the 2008 Surviving Sepsis Campaign Guidelines [51], a review by Vincent et al. [52] on circulatory shock and Trof et al. showed a more rapid change in SV with colloid boluses [53]. We delivered our volume challenge within fifteen minutes which is in keeping with the other studies.

Secondly, we measured CO using a single non-calibrated device and did not include a second calibrated device. However, the study by Biais et al. [28] had simultaneously measured haemodynamic changes during PLR with the Vigileo $^{\text {Tx }}$ monitor and transthoracic echocardiography and found that the changes induced by volume expansion correlated well between these two devices $\left(r^{2}=0.77, p<\right.$ 0.0001). This was despite Biais et al. using the less accurate second-generation Vigileo software (version 1.14). In addition, several studies have validated the Vigileo third-generation software in the patient population we recruited. Meng et al. [46] assessed the trending ability of the Vigileo third-generation software using directly measured Oesophageal Doppler blood flow as the comparison device and found that the two devices showed $96 \%$ concordance when measuring a change in preload induced by whole body tilting. De Backer et al. [45] reported acceptable accuracy using the thirdgeneration software in patients with vasoplegia (septic shock and liver failure) as did Slagt et al. [47] in a systematic review comparing the different generations of Vigileo software. Despite the absence of a second calibrated device in our study, we derived a similar optimal cut point as the other published PLR studies $[21-41,49,50]$ and specifically in the subgroups that also used pulse contour methods [28, 30-33].

Thirdly, in the majority of our patients (88 \%), measurement was via a peripheral artery which may be less accurate than via a central artery in vasodilated patients [54]. The number receiving a central (femoral) arterial catheter was too few to analyse for this effect.

Finally, $39 \%$ of the patients included in our study were surgical and therefore had the potential for intra-abdominal hypertension which has been shown by Mahjoub et al. [50] to reduce the accuracy of PLR for predicting fluid responsiveness. We did not have sufficient data on intraabdominal pressures to analyse for this effect.

\section{Conclusions}

We have demonstrated that changes in cardiac output measured using the Vigileo $^{\mathrm{Tu}}$ monitor with thirdgeneration software during a PLR test were predictive of fluid responsiveness in both medical and surgical patients with vasopressor-dependent circulatory shock. As the $\mathrm{EV} 1000^{\text {in }}$ monitoring system, which has replaced the Vigileo $^{\mathrm{Tm}}$ monitor, continues to use the third-generation software for the FloTrac device these findings remain valid.

\section{Additional file}

Additional file 1: Study dataset. (CSV $8 \mathrm{~kb}$ )

\section{Abbreviations}

AUC: Area under the receiving operating characteristic curve; CO: Cardiac output; PLR: Passive leg raise; PVE: Post volume expansion; SV: Stroke volume; TTE: Transthoracic echocardiography; VE: Volume expansion

\section{Acknowledgements}

Lynne Bullock and Donna Harrison-Briggs participated in the data collection. This study received no financial support. The Vigileo ${ }^{\mathrm{TM}}$ monitor $\left(V_{\text {Vigileo }}{ }^{\mathrm{TM}}\right.$; FloTrac; Edwards ${ }^{\mathrm{TM}}$; Lifesciences, Irvine, CA, USA) was part of our routine flow monitoring on our critical care unit for 3 years prior to this study.

\section{Funding}

This study was undertaken by the authors and the acknowledged members of the clinical team without any external funding.

\section{Availability of data and material}

The dataset supporting the conclusions of this article is included within the article (and its Additional file 1).

\section{Authors' contributions}

AK conceived and designed the study, participated in the data collection and drafted the manuscript. MB participated in the data collection and contributed to drafting the manuscript. TF provided the statistical analysis and contributed to drafting the manuscript. AK has full access to all the study data and takes responsibility for data integrity and accuracy of data analysis. All authors read and approved the final manuscript.

\section{Competing interests}

The authors declare that they have no competing interests.

\section{Consent for publication}

Not applicable.

\section{Ethics approval}

The UK NRES Bolton Research Ethics Committee (REC reference number 08/ H1009/61) approved the study.

\section{Author details}

${ }^{1}$ Department of Anaesthesia and Critical Care, Royal Blackburn Hospital, Haslingden Road, Blackburn, UK. ${ }^{2}$ Nuffield Department of Primary Care Health Sciences, University of Oxford, Oxford, UK

Received: 12 April 2016 Accepted: 27 September 2016

Published online: 06 October 2016

\section{References}

1. Rivers E, Nguyen B, Havstad S, Ressler J, Muzzin A, Knoblich B, Peterson E, Tomlanovich $\mathrm{M}$. Early goal-directed therapy in the treatment of severe sepsis and septic shock. N Engl J Med. 2001;345:1368-77.

2. Kumar A, Anel R, Bunnell E, Habet K, Zanotti S, Marshall S, Neumann A, Ali A, Cheang $M$, Kavinsky C, Parillo J. Pulmonary artery occlusion pressure and central venous pressure fail to predict ventricular filling volume, cardiac performance, or the response to volume infusion in normal subjects. Crit Care Med. 2004;32(3):691-9.

3. Michard F, Teboul JL. Predicting fluid responsiveness in ICU patients: a critical analysis of the evidence. Chest. 2002;121:2000-8. 
4. Alsous F, Khamiees M, DeGirolamo A, Amoateng-Adjepong Y, Manthous CA Negative fluid balance predicts survival in patients with septic shock. Chest. 2002;117:1749-54

5. Holte K, Kehlet H. Fluid therapy and surgical outcomes in elective surgery: a need for reassessment in fast-track surgery. J Am Coll Surg. 2006;202:971-89.

6. Wiedemann HP, Wheeler AP, Bernard GR, et al. Comparison of two fluidmanagement strategies in acute lung injury. N Engl J Med. 2006;354:2564-75.

7. Boyd JH, Forbes J, Nakada TA, et al. Fluid resuscitation in septic shock: a positive fluid balance and elevated central venous pressure are associated with increased mortality. Crit Care Med. 2011;39:259-65.

8. Nisanevich V, Felsenstein I, Almogy G, et al. Effect of intraoperative fluid management on outcome after intra-abdominal surgery. Anesthesiology. 2005;103:25-32.

9. Bundgaard-Nielsen $\mathrm{M}$, Secher $\mathrm{NH}$, Kehlet $\mathrm{H}$. 'Liberal' vs. 'restrictive' perioperative fluid therapy - a critical assessment of the evidence. Acta Anaesthesiol Scand. 2009;53:843-51.

10. Holte K, Klarskov B, Christensen DS, et al. Liberal versus restrictive fluid administration to improve recovery after laparoscopic cholecystectomy: a randomized, double-blind study. Ann Surg. 2004;240:892-9.

11. Weidemann HP, Wheeler AP, Bernard GR, Thompson BT, Hayden D, deBoisblanc B, Connors Jr AF, Hite RD, Harabin AL. Comparison of two fluid management strategies in acute lung injury. N Engl J Med. 2006;354:2564-75.

12. Cavallaro F, Sandroni C, Antonelli M. Functional hemodynamic monitoring and dynamic indices of fluid responsiveness. Minerva Anestesiol. 2008;74:137-43.

13. Marik PE, Cavallazzi R, Vasu T, Hirani A. Dynamic changes in arterial waveform derived variables and fluid responsiveness in mechanically ventilated patients: a systematic review of the literature. Crit Care Med. 2009;37:2642-7.

14. Michard F, Teboul JL. Using heart-lung interactions to assess fluid responsiveness during mechanical ventilation. Crit Care. 2000:4:282-9.

15. Perner A, Faber T. Stroke volume variation does not predict fluid responsiveness in patients with septic shock on pressure support ventilation. Acta Anaesthesiol Scand. 2006;50:1068-73.

16. Hofer CK, Senn A, Weibel L, Zollinger A. Assessment of stroke volume variation for prediction of fluid responsiveness using the modified FloTrac and PiCCOplus system. Crit Care. 2008:12:R82.

17. Soubrier S, Saulnier F, Hubert H, Delour P, Lenci H, Onimus T, Nseir S, Durocher A. Can dynamic indicators help the prediction of fluid responsiveness in spontaneously breathing critically ill patients? Intensive Care Med. 2007;33: $1117-24$.

18. Rutlen DL, Wackers FJ, Zaret BL. Radionuclide assessment of peripheral intravascular capacity: a technique to measure intravascular volume changes in the capacitance circulation in man. Circulation. 1981;64:146-52.

19. Gaffney FA, Bastian $B C$, Thal ER, et al. Passive leg raising does not produce a significant or sustained autotransfusion effect. J Trauma. 1982;22:190-3.

20. Wong DH, O'Connor D, Tremper KK, et al. Changes in cardiac output after acute blood loss and position change in man. Crit Care Med. 1989;17:979-83.

21. Boulain T, Achard JM, Teboul JL, Richard C, Perrotin D, Ginies G. Changes in BP induced by passive leg raising predict response to fluid loading in critically ill patients. Chest. 2002;121:1245-52.

22. Lafaneche're A, P'ene F, Goulenok C, Delahaye A, Mallet V, Choukroun G Chiche JD, Mira JP, Cariou A. Changes in aortic blood flow induced by passive leg raising predicts fluid responsiveness in critically ill patients. Crit Care. 2006;10:R132-40.

23. Monnet X, Rienzo M, Osman D, Anguel N, Richard C, Pinsky MR, Teboul JL. Passive leg raising predicts fluid responsiveness in the critically ill. Crit Care Med. 2006;34:1402-7.

24. Thiel SW, Kollef MH, Isakow W. Non-invasive stroke volume measurement and passive leg raising predicts volume responsiveness in medical ICU patients: an observational cohort study. Crit Care. 2009;13:R111-20

25. Lamia B, Ochagavia A, Monnet X, Chemla D, Richard C, Teboul JL. Echocardiographic prediction of volume responsiveness in critically ill patients with spontaneous breathing activity. Intensive Care Med. 2007; 33:1133-8.

26. Maizel J, Airapetian N, Lorne E, Tribouilloy C, Massy Z, Slama M. Diagnosis of central hypovolemia by using passive leg raising. Intensive Care Med. 2007;33:1133-8.

27. Caille V, Jabot J, Belliard G, Charron C, Jardin F, Vieillard-Baron A. Hemodynamic effects of passive leg raising: an echocardiographic study in patients with shock. Intensive Care Med. 2008;34:1239-45.

28. Biais M, Vidil L, Sarrabay P, Cottenceau V, Revel P, Sztark F. Changes in stroke volume induced by passive leg raising in spontaneously breathing patients: comparison between echocardiography and Vigileo TM/FloTracTM device. Crit Care. 2009;13:R195.

29. Pr'eau S, Saulnier F, Dewavrin F, Durocher A, Chagnon JL. Passive leg raising is predictive of fluid responsiveness in spontaneous breathing patients with severe sepsis or acute pancreatitis. Crit Care Med. 2010;38:819-25.

30. Lakhal K, Ehrmann S, Runge I, et al. Central venous pressure measurements improve the accuracy of leg raising-induced change in pulse pressure to predict fluid responsiveness. Intensive Care Med. 2010;36:940-8.

31. Kang WS, Kim SH, Kim SY, Oh CS, Lee SA, Kim JS. The influence of positive endexpiratory pressure on stroke volume variation in patients undergoing cardiac surgery: an observational study. J Thorac Cardiovasc Surg. 2014;148:3139-45.

32. Geerts $B$, de Wilde $R$, Aarts $L$, et al. Pulse contour analysis to assess hemodynamic response to passive leg raising. J Cardiothorac Vasc Anesth. 2011;25:48-52.

33. Dong ZZ, Fang $Q$, Zheng $X$, et al. Passive leg raising as an indicator of fluid responsiveness in patients with severe sepsis. World J Emerg Med. 2012;3:191-6.

34. Benomar B, Ouattara A, Estagnasie $\mathrm{P}$, et al. Fluid responsiveness predicted by noninvasive bioreactance-based passive leg raise test. Intensive Care Med. 2010;36:1875-81.

35. Marik PE, Levitov A, Young A, et al. The use of bioreactance and carotid Doppler to determine volume responsiveness and blood flow redistribution following passive leg raising in hemodynamically unstable patients. Chest. 2013;143:364-70.

36. Duus N, Shogilev DJ, Skibsted S, et al. The reliability and validity of passive leg raise and fluid bolus to assess fluid responsiveness in spontaneously breathing emergency department patients. J Crit Care. 2015;30:217.e1-5.

37. Monge García MI, Gil Cano A, Gracia Romero M, et al. Non-invasive assessment of fluid responsiveness by changes in partial end-tidal $\mathrm{CO}_{2}$ pressure during a passive leg-raising maneuver. Ann Intensive Care. 2012;2:9.

38. Fellahi $\mathrm{L}$, Fischer MO, Dalbera A, et al. Can endotracheal bioimpedance cardiography assess hemodynamic response to passive leg raising following cardiac surgery? Ann Intensive Care. 2012;2:26.

39. Cavallaro F, Sandroni C, Marano C, La Torre G, Chiara A, De Waure C, Bello G, Maviglia R, Antonelli M. Diagnostic accuracy of passive leg raising for prediction of fluid responsiveness in adults: systematic review and metaanalysis of clinical studies. Intensive Care Med. 2010;36:1475-83.

40. Monnet X, Marik P, Teboul J-L: Passive leg raising for predicting fluid responsiveness: a systematic review and meta-analysis. Intensive Care Med. published online 20th Jan 2016

41. Chernapath TGV, Hirsch A, Geerts BF, et al. Predicting fluid responsiveness by passive Leg raising: a systematic review and meta-analysis of 23 clinical trials. Crit Care Med. 2016;44(5):981-91.

42. Cheng $L$, Lin F-q, Shu-kun F, et al. Stroke volume variation for prediction of fluid responsiveness in patients undergoing gastrointestinal surgery. Int J Med Sci. 2013;10(2):148-55.

43. Langewouters GJ, Wesseling KH, Goedhard WJ. The pressure dependent dynamic elasticity of 35 thoracic and 16 abdominal human aortas in vitro described by a five component model. J Biomech. 1985;18:613-20.

44. Pratt B, Roteliuk L, Hatib F, Frazier J, Wallen RD. Calculating arterial pressurebased cardiac output using a novel measurement and analysis method. Biomed Instrum Technol. 2007:41:403-11.

45. De Backer D, Marx G, Tan A, et al. Arterial pressure-based cardiac output monitoring: a multicenter validation of the third-generation software in septic patients. Intensive Care Med. 2011;37:233-40.

46. Meng L, Tran PS, Brenton AS, Lanning K, et al. The impact of phenyephrine, ephedrine and increased preload on the third-generation Vigileo-Flotrac and esophageal Doppler cardiac output measurements. Anesth Analg. 2011;113:751-7.

47. Slagt C, Malagon I, Groeneveld ABG. Systematic review of uncalibrated arterial pressure waveform analysis to determine cardiac output and stroke volume variation. Br J Anaesth. 2014;112(4):626-37.

48. R Development Core Team (2008). R: a language and environment for statistical computing. R Foundation for Statistical Computing. Vienna, Austria. ISBN 3-900051-07-0, URL http://www.R-project.org.

49. Jabot J, Teboul JL, Richard C, Monnet $X$. Passive leg raising for predicting fluid responsiveness: importance of the postural change. Intensive Care Med. 2009;35:85-90.

50. Mahjoub Y, Touzeau J, Airapetian N, Lorne E, Hijazi M, Zogheb E, Tinturier F, Slama M, Dupont $\mathrm{H}$. The passive leg-raising maneuver cannot accurately predict fluid responsiveness in patients with intra-abdominal hypertension. Crit Care Med. 2010;38(9):1824-9. 
51. Dellinger RP, Levy MM, Carlet JM, et al. Surviving sepsis campaign: international guidelines for management of severe sepsis and septic shock. Crit Care Med. 2008;36:296-327.

52. Vincent JL, Weil MH. Fluid challenge revisited. Crit Care Med. 2006:34:1333-7.

53. Trof RJ, Sukul SP, Twisk JW, et al. Greater cardiac response of colloid than saline fluid loading in septic and non-septic critically ill patients with clinical hypovolaemia. Intensive Care Med. 2010;36:697-701.

54. Dorman T, Breslow MJ, Lipsett PA, Rosenberg JM, Balser JR, Almog Y, Rosenfeld BA. Radial artery pressure monitoring underestimates central arterial pressure during vasopressor therapy in critically ill surgical patients. Crit Care Med. 1998;26:1646-9.

Submit your next manuscript to BioMed Central and we will help you at every step:

- We accept pre-submission inquiries

- Our selector tool helps you to find the most relevant journal

- We provide round the clock customer support

- Convenient online submission

- Thorough peer review

- Inclusion in PubMed and all major indexing services

- Maximum visibility for your research

Submit your manuscript at www.biomedcentral.com/submit
) Biomed Central 